\title{
Bridge Engineering: Referees 2018
}

The following is a list of referees who have reviewed papers for Bridge Engineering between 1 December 2017 and 30 November 2018. The Institution of Civil Engineers is very grateful for their assistance.

We are continually looking for suitable reviewers for papers submitted to Bridge Engineering. Papers published in the Proceedings of the ICE must be submitted to at least two independent referees to judge accuracy, style, impact, importance and interest.

If you are interested in reviewing articles on any topic related to bridge engineering, please submit your name, qualifications or CV,

William Addis

Mehrdad Aghagholizadeh

Reza Akbari

Tony Ambrose

Miguel Astiz

Hussein Aziz

Andrew Bance

James Banks

Saprava Bhattacharya

Fabio Biondini

Thanos Bistolas

Thomas Boothby

Simon Bourne

Philip Brown

Andrea Caristo
Joan Casas

Shengbo Chai

Lucio Chiodi

Peter Clapham

Richard Clough

David Collings

John Collins

Richard Cooke

Lee Cunningham

Jeremy Cutter

Albert Daly

Julian De Voy

Luigi Di-Sarno

Marco Domaneschi

James Dow and areas of expertise. We are in need of individuals who will agree to review papers in a timely fashion (within 3 to 4 weeks of receipt) and provide confidential feedback to the Editorial Advisory Panel concerning the quality of the paper and any suggested revisions that would be appropriate.

If you are such a person, please contact Kirsten Buchanan (tel.: +44 (0)207 665 2204; e-mail: kirsten.buchanan@icepublishing.uk) for more information on the referee process.

Liam Duffy
Fabio Gazzola
Graham Gedge
Dave Gent
Craig Giaccio
Donya Hajializadeh
Andrew Hodgkinson
Paul A. Jackson
Stephen Jones
Sivakumar Kandasami
Sameer Khan
Ray Langley
Erik Larsen
Fang Li
Angus Low

Padraig McCarron Luis Carlos Mendes Stergios Mitoulis Alan Monnickendam José Oliveira Pedro Rusi Rusev Hossam El-Din Sallam Jose Santos Graham Slade Mungo Stacy Riccardo Stroscio Jose Turmo Cor Van Der Veen Hongbing Xie Hoe-Chian Yeow 